\title{
Effect of aerobic exercise and corn peptide on fat metabolism of overweighed and obese female college students.
}

\author{
Lei $\mathrm{Hu}^{1^{*}}$
}

Chongqing Technology and Business university, Institute of Physical Education, No.19 Xuefu Rode, Nanan District, Chongqing, PR China

\begin{abstract}
Objective: This research is aimed to explore the effect of aerobic exercise and corn peptide on fat metabolism of overweighed and obese female college students.

Methods: 30 female college students were selected and randomly divided into two groups. Both groups received aerobic exercise. On this basis, the corn peptide group was given corn peptide while the control group was given the same quantity of protein powder. After the experiment, the change of BMI, lipase, and plasma free fatty acid of both groups were compared.

Results: The BMI, body mass, and body fat rate of the corn peptide group were lower than the control group. The difference was statistically significant $(P<0.05)$. The plasma free fat acid level and lipase activity of the corn peptide group were significantly higher than the control group. The difference was statistically significant $(P<0.05)$. After experiment, the TC, TG, LDL, and HDL of the corn peptide group were improved. The difference was statistically significant $(\mathbf{P}<\mathbf{0 . 0 5})$.

Conclusion: Corn peptide combined with aerobic exercise (for 8 weeks) can effectively improve the body fat rate and BMI among overweighed and obese female college students.
\end{abstract}

Keywords: Aerobic exercise, Corn peptide, Obesity, Overweight, Female college students.

Accepted on June 13, 2017

\section{Introduction}

Obesity or overweight is a disease caused by bad eating habits, abnormal energy metabolism, excessive fat accumulation, and abnormal endocrine system metabolism due to environmental and genetic factors [1]. It is not only an independent risk factor for clinical cardiovascular disease, but as one of the greatest challenges to the public health. According to clinical survey, adult obesity increases about $30 \%$ per year in China. Children obesity also appears frequently at present [2,3]. Therefore, obesity has become one of the most important adverse factors that affect society and families, which should draw wide attention. Among obese group, the proportion of female increases year by year, which may be caused by busy working and lack of exercise [4]. Aerobic exercise is popular among the people. It can help control weight by improving total energy consumption and reducing body fat rate. Corn peptide is a small molecular peptide with natural activity. It is rich in branched chain amino acid including Lucien, which can lower blood pressure, speed up alcohol metabolism, prevent fatigue and protect liver [5]. There is hardly any studies on female weight loss studies using corn peptide. Therefore, we conducted the study to explore the effect of aerobic exercise and corn peptide on fat metabolism of overweighed and obese female college students and provide reliable reference and data in the field of female weight loss.

\section{Documentation and Methods}

\section{General data}

In this study, 30 female college students were selected and randomly divided into control group and experimental group, with 15 in each group. Female students in the control group ranges from 19 to 23 years old, with average age of $21.25 \pm$ 1.35 years old; height ranges from 1.50 to $1.75 \mathrm{~m}$, with average height of $1.58 \pm 0.32 \mathrm{~m}$, body mass ranges from 59 to $80 \mathrm{~kg}$, with average body mass of $63.15 \pm 4.47 \mathrm{~kg}$; and BMI ranges from 25 to $28.5 \mathrm{~kg} \cdot \mathrm{m}^{-2}$, with average BMI of $26.35 \pm 1.83$ $\mathrm{kg} \cdot \mathrm{m}^{-2}$. Female students in the corn peptide group ranges from 20 to 23 years old, with average age of $22.39 \pm 1.02$ years old; height ranges from 1.51 to $1.73 \mathrm{~m}$, with average height of 1.56 $\pm 0.24 \mathrm{~m}$, body mass ranges from 60 to $79 \mathrm{~kg}$, with average body mass of $62.53 \pm 4.44 \mathrm{~kg}$; and $\mathrm{BMI}$ ranges from 24 to 28.5 $\mathrm{kg} \cdot \mathrm{m}^{-2}$, with average BMI of $26.40 \pm 1.85 \mathrm{~kg} \cdot \mathrm{m}^{-2}$. Three standards included in this study: 1) According to obesity standard, namely BMI is not less than 24 . Normal BMI ranges from 18.5 to 23.9. Overweight BMI ranges from 24 to 27.9, and obese BMI is greater than 28. 2) No quitting during this study. 3) No exercise contraindications. After comparison of general data, including age and BMI of both groups, there is no significant difference $(\mathrm{P}>0.05)$. Subjects in both groups are 
aware of this study and volunteered to sign the informed consent form.

\section{Research methods}

Subjects in both groups received aerobic exercise from 17:00 to 18:00 every Monday, Wednesday, Friday, and Sunday for 60 min. Subjects received aerobic bodybuilding exercise on Monday, Wednesday, and Friday, and jogging and shape-up exercise on Sunday. The exercise intensity was controlled between $60 \%$ to $80 \%$ of maximum heart rate, which lies in 120 to 140 times $/ \mathrm{min}$. Background music is controlled at 130 beats/ min. Each exercise includes $10 \mathrm{~min}$ preparation, $40 \mathrm{~min}$ aerobic exercise, and $10 \mathrm{~min}$ relaxing [6]. On the basis of above exercise, the corn peptide group received oral corn peptide (produced by Hubei Reborn Biological Technology) one time a day for $20 \mathrm{~g}$. The control group received protein powder of the same quantity. During 8 weeks of the study, subjects in both groups adjusted their diet habits, with controlling the intake of high calorie and fat, taking more vegetables, stopping alcohol and night snack, and reducing intake of irritable and high salt food. What's more, they kept normal schedule and prevent heavy labor and other exercises beside PE class $[7,8]$. Through symposiums and face to face conversation, researchers can help subjects to change their bad diet and exercise habits to build correct concept and good attitude to weight loss. This weight loss program was strictly carried out by strengthening weight loss perseverance and their compliance.

\section{Observation indexes}

The observation indexes in this study includes BMI, skinfold thickness, free fatty acid, and lipase activity. Body mass need to be measured in the morning on an empty stomach condition, wearing light clothes. Skinfold thickness is measured by skinfold thickness equipment. Subjects need to provide elbow vein blood on fasting state to detect indexes including lipase activity, free fatty acid, triglycerides, and total cholesterol [9-11].

\section{Statistical analysis}

SPSS 18.0 was used for statistical analysis, $\overline{\mathrm{x}} \pm \mathrm{s}$ was used for measurement data, and $\mathrm{t}$ test was used to compare the differences of the two groups. $\mathrm{P}<0.05$ was considered to indicate a statistically significant difference.

\section{Results}

\section{Relationship between corn peptide and body composition}

Compared with values before this study, the BMI, body mass, and body fat rate of subjects in the corn peptide reduced significantly, with $\mathrm{P}<0.05$. After experiment, the BMI, body mass, and body fat rate of the corn peptide group were significantly lower than the control group $(\mathrm{P}<0.05)$. After experiment, the abdominal and waist skinfold thickness of both groups reduced. Subjects in corn peptide group decreased markedly $(\mathrm{P}<0.05)$. After experiment, the abdominal and waist skinfold thickness of the corn peptide group were less than the control group $(\mathrm{P}<0.05)$ and the details was shown in Table 1.

Table 1. Body composition comparison of both groups before and after experiment $(\bar{x} \pm s)$.

\begin{tabular}{|c|c|c|c|c|}
\hline \multirow{2}{*}{ Index } & \multicolumn{2}{|c|}{ Control group } & \multicolumn{2}{|c|}{ Corn peptide group } \\
\hline & Before experiment & After experiment & Before experiment & After experiment \\
\hline Body mass (kg) & $63.15 \pm 4.47$ & $61.86 \pm 4.22$ & $62.53 \pm 4.44$ & $58.75 \pm 4.76^{* \#}$ \\
\hline Body fat rate $(\%)$ & $28.54 \pm 2.66$ & $27.68 \pm 2.83$ & $28.18 \pm 1.29$ & $23.31 \pm 2.42^{* \#}$ \\
\hline BMI $\left(\mathrm{kg} \cdot \mathrm{m}^{-2}\right)$ & $26.35 \pm 1.83$ & $25.63 \pm 1.80$ & $26.40 \pm 1.85$ & $24.27 \pm 1.23^{* \#}$ \\
\hline Body fat mass (kg) & $17.77 \pm 2.25$ & $17.28 \pm 2.20$ & $17.92 \pm 2.75$ & $16.65 \pm 2.57^{\#}$ \\
\hline FFM (kg) & $44.65 \pm 2.50$ & $43.81 \pm 2.46$ & $43.95 \pm 2.87$ & $44.61 \pm 2.92$ \\
\hline $\begin{array}{l}\text { Abdominal Skinfold Thickness } \\
(\mathrm{mm})\end{array}$ & $29.74 \pm 1.46$ & $28.93 \pm 1.31$ & $30.11 \pm 1.60$ & $27.55 \pm 1.58$ \\
\hline Waist Skinfold Thickness (mm) & $27.95 \pm 0.86$ & $27.35 \pm 0.96$ & $28.03 \pm 0.95$ & $26.44 \pm 0.71$ \\
\hline
\end{tabular}

Note: Compared with values before experiment, ${ }^{*}$ means $\mathrm{P}<0.05$; Compared with the same group, \#means $\mathrm{P}<0.05$.

Table 2. Free fatty acid and lipase comparison between both groups before and after experiment $(\bar{x} \pm s)$.

\begin{tabular}{lccc}
\hline & \multicolumn{2}{c}{ Control group } & \multicolumn{2}{c}{ Corn peptide group } \\
\cline { 2 - 4 } Index & Before experiment & After experiment & Before experiment \\
\hline
\end{tabular}




\begin{tabular}{lllll}
\hline Free fatty acid & $726.05 \pm 378.20$ & $843.44 \pm 438.89^{*}$ & $692.06 \pm 415.32$ & $907.81 \pm 368.42^{* \#}$ \\
\hline Lipase & $63.56 \pm 43.27$ & $70.75 \pm 43.96^{*}$ & $65.15 \pm 41.14$ & $79.33 \pm 35.25^{* \#}$ \\
\hline
\end{tabular}

Note: Compared with values before experiment, " means $\mathrm{P}<0.05$; Compared with the same group, ${ }^{*}$ means $\mathrm{P}<0.05$.

\section{Relationship between corn peptide and free fatty acid and lipase}

After experiment, the free fatty acid and lipase activity of both groups increased. Subjects in the corn peptide group increased notablely. The difference was statistically significant, with $\mathrm{P}<0.05$. The free fatty acid level and lipase activity of the corn peptide group were higher than the control group $(\mathrm{P}<0.05)$ and the details were shown in Table 2.

\section{Relationship between corn peptide and blood fat test}

Compared with values before experiment, the blood fat index of both groups improved, and the corn peptide group was higher. After experiment, the TC, TG, LDL, and HDL of the corn peptide group were better. The difference was statistically significant, with $\mathrm{P}<0.05$. After experiment, the TC, TG, LDL, and HDL of the corn peptide group were better than the control group. The difference was statistically significant, with $\mathrm{P}<0.05$, and the details were shown in Table 3.

Table 3. Comparison of blood fat test index of both groups before and after experiment (xs).

\begin{tabular}{lllll}
\hline \multirow{2}{*}{ Index } & \multicolumn{2}{c}{ Control group } & \multicolumn{2}{c}{ Corn peptide group } \\
\cline { 2 - 5 } & $\begin{array}{l}\text { Before } \\
\text { experiment }\end{array}$ & $\begin{array}{l}\text { After } \\
\text { experiment }\end{array}$ & $\begin{array}{l}\text { Before } \\
\text { experiment }\end{array}$ & $\begin{array}{l}\text { After } \\
\text { experiment }\end{array}$ \\
\hline $\mathrm{TC}(\mathrm{mmol} / \mathrm{L})$ & $4.79 \pm 0.08$ & $4.73 \pm 0.09$ & $4.78 \pm 0.09$ & $4.52 \pm 0.11^{*}$ \\
\hline $\mathrm{TG}(\mathrm{mmol} / \mathrm{L})$ & $1.61 \pm 0.11$ & $1.55 \pm 0.09$ & $1.60 \pm 0.11$ & $1.38 \pm 0.10^{* \#}$ \\
\hline $\mathrm{LDL}(\mathrm{mmol} / \mathrm{L})$ & $2.71 \pm 0.11$ & $2.62 \pm 0.12$ & $2.71 \pm 0.12$ & $2.55 \pm 0.13^{*}$ \\
\hline $\mathrm{HDL}(\mathrm{mmol} / \mathrm{L})$ & $1.46 \pm 0.11$ & $1.66 \pm 0.09$ & $1.47 \pm 0.12$ & $1.54 \pm 0.09^{* \#}$ \\
\hline $\begin{array}{l}\text { Note: Compared with values before experiment, } \\
\text { with the same group, }{ }^{*} \text { means } \mathrm{P}<0.05 .\end{array}$ & & $\mathrm{P}<0.05 ;$ Compared \\
\hline
\end{tabular}

\section{Discussion}

According to clinical investigations the number of obese and overweight college students increases year by year. Obesity is closely associated with many chronic diseases, affecting physical appearance, and forms obstacles in social activities, employment, and mate selection [12]. At present, intervention researches on weight loss of college students has been emphasized in the public health field. Related researches are mainly focused on exercise and diet control. This study is no exception. There are many kins of exercises for weight loss, such as HIT and aerobic exercise [13-15]. As is reported, long term aerobic exercise can effectively improve the utilization of fat and speed up fat metabolism. In this study, female college students in the corn peptide group received aerobic exercise of 8 weeks. Their free fatty acid and lipase activity significantly increased, which means aerobic exercise can help improve the lipase activity including hepatic lipase and lipoprotein lipase.

Corn peptide is the mixed substance obtained by corn protein processing. Its molecular weight is under $1000 \mathrm{Da}$, which makes it directly absorbed by human body. In this study, the female college students in the corn peptide group received aerobic exercise combined with oral corn peptide. Their TC, TG, and LDL levels were significantly lower than the control group and levels before experiment. Their HLD was significantly higher than the control group and before experiment. The difference was statistically significant. That is to say, corn peptide combining aerobic exercise can effectively improve the blood fat metabolism level of female college students. What's more, the abdominal and waist skinfold of the female college students in the corn peptide group were significantly lower than the control group and before experiment. That is to say, the combination of corn peptide and aerobic exercise have positive role on the weight loss in female college students. In conclusion, the combination of corn peptide and aerobic exercise (for 8 weeks) can effectively improve the body fat rate and BMI among overweight and obese female college students.

\section{References}

1. Liqian X. Influence of Comprehensive Intervention Plan on Blood Fat Metabolism of Obese Female College Students. Beijing Sport University 2015.

2. Daohua Z, Quanfu Z, Lingying M. Influence of exercise fat lose intervention on physical signs of obese female college students. Contemporary Sports Technol 2014; 4: 13-14.

3. Junru N. Influence of aerobic exercise and low gi/gl diet on weight loss effect and aerobic endurance of female college students. Shanghai, East China Normal University, 2016.

4. Lin L, Jia L, Xiaohui W. Influence of aerobic exercise and corn peptide on key fat decomposition enzyme by obese mouse. Chinese J Appl Physiol 2016; 32: 326-331.

5. Xiangyang T, Tianshuai P, Rengfei S. The effect of corn peptide on plasma ffa and lps of overweight and obesity female college students. J Guiyang Med Coll 2015; 40: 975-977.

6. Beibei L. Effects of aerobic exercise on obese university female students' body morphology, physiological functions and blood lipid. J Shangqiu Normal University 2015; 31: 131-134.

7. Tianxiao L, Jia L, Guanhua Z. Aerobic exercise with cassia tea for female college students body shape and lipid metabolism. Shandong Sports Sci Technol 2012; 34: 34-38. 
8. Rui W. Research on problems and intervention of aerobic exercise of female college students. Nanjing Normal University, Nanjing, 2015.

9. Wenxin X, Jiwei Y. Review and outlook of weight losing by exercising during last ten years. J Jilin Institute Physical Education 2011; 5: 16-18.

10. Zheng W, Fuxiang D, Yuliu T. Research on exercise prescription for obese female college students. J Suzhou University (Natural Science) 2012; 28: 90-94.

11. Zhonghua $H$. The influence of bmd by individual interference on losing weight among obesity girl students. Zhejiang Sport Sci 2015; 37: 102-105.

12. Tian Q, Yonglan L, Liangzhen L. Effect of different exercise methods on the weight loss of obese college students. J Ningde Teachers College (Natural Science) 2016; 28: 71-74.

13. Yugang Q, Jinhong H, Sijie T. Comparison of weight loss effects carried out by hit and continuous aerobic exercise of female college students. China Sport Sci Technol 2013; 49: 30-33.

14. Jianhua H. Effect of 8 weeks diet and exercise intervention on physiological parameters, blood lipid and insulin of obese female college students. Zhejiang Sport Sci 2013; 35: 124-128.

15. Pingxiu W, Zhiping X. Influences of "Weight-Losing Exercise Prescription" on physical and mental health of obesity female college students. J Shenyang Sport University 2009; 28: 71-73.

\section{*Correspondence to}

Lei $\mathrm{Hu}$

Chongqing Technology and Business University

Chongqing City

PR China 